تأثير تقنيات التطريز الآلي علي هظهرية أقششة الساتان

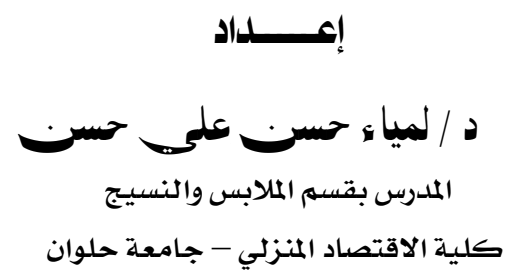

مجلة بحوث التربية النوعية - جامعة المنصورة

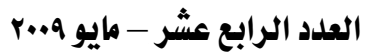




\title{
تأثير تقنيات التطريز الآلي علي هظهرية أقمشة الساتان
}

\author{
إعـــداد
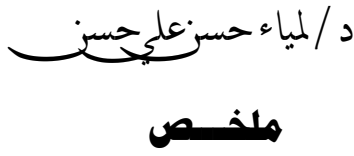 \\ يهـف البحـث إلى التعـرف على أثر اختلاف مستوي كثافة غرز التطريز - نوع الخيط -

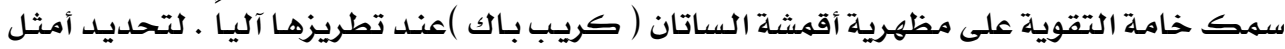

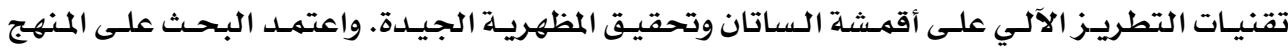

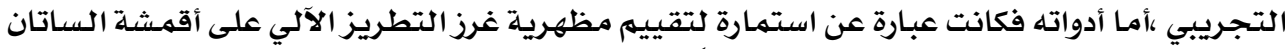

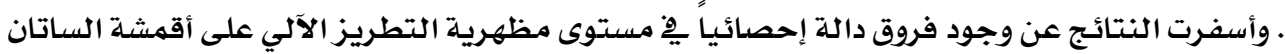

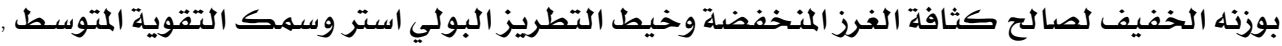

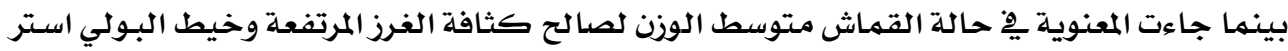

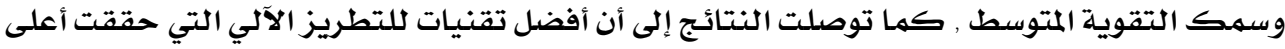

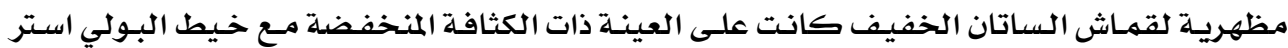

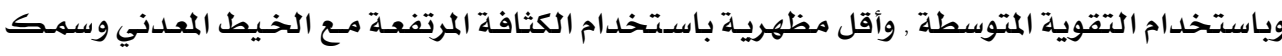 \\ التقوية الخفيف ـ أما بالنسبة للساتان متوسط الوزن فكانت العينـات ذات الكثافة المرتفعـة باستخدام

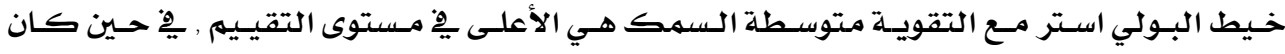 \\ المستوى الأقل مـع العينات ذات الكثافة المنخفضفة والخيط المعدني والتقوية خفيفة السمك.
}




\section{Summary}

\section{"The effect of automatic embroidery techniques on Satin fabrics appearance "}

The research aims to identify the effect of the different level of density of embroidery stitches - the type of thread - the thickness of supporting material on the appearance of Satins (crepe back) when embroidering .To determine the optimal techniques for good appearance of satin fabrics automated embroidery. The research depends on experimental curriculum, its tools were a form to evaluate the appearance of automated embroidery stitches on satin fabrics. Resulted in findings of the existence of a statistical differences in the embroidery appearance on the light-weight fabrics, for the low density stitches, polyester embroidery thread, and the medium thickness of supporting material, while a statistical deference in the medium weight of satin fabric for the high density of stitches, polyester thread and the medium thickness of the supporting material, also results reached that the best embroidery techniques which achieved the highest appearance quality of the light satin fabric was on the sample with low-density, polyester thread and the use of medium supporting material, and the less appearance was by using high stitches density, the metal thread, light supporting material. As for the medium weight of Satin was of the sample with high stitches-density, polyester thread with the medium thickness of supporting material is the highest level of evaluation, while the lower level of the sample with low-density, metal thread and light supporting material. 


\section{تأثير تقنيات التطريز الآلي علي هظهرية أقمشة الساتان}

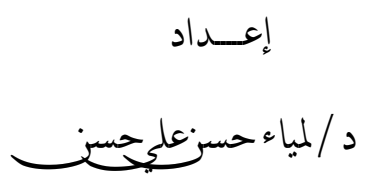

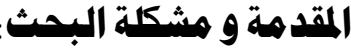

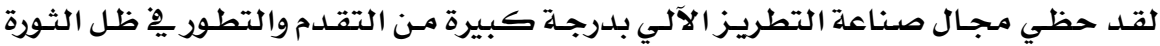

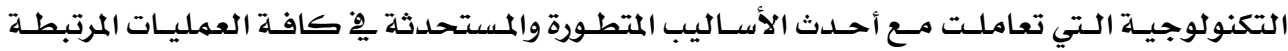

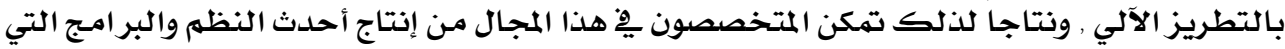

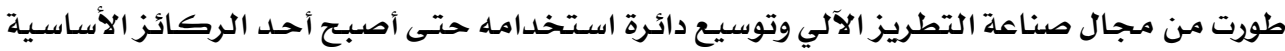

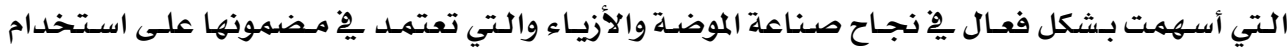

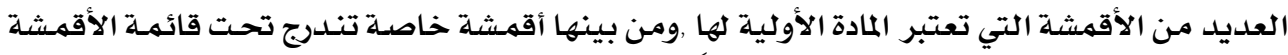

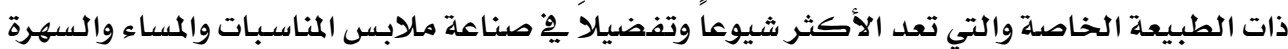

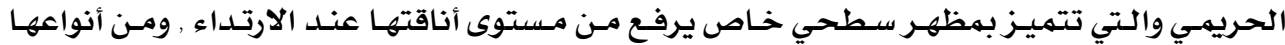

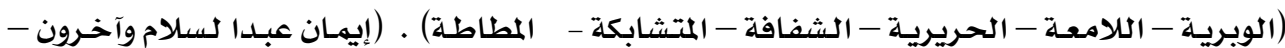

(rq - r...r

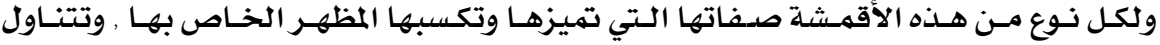

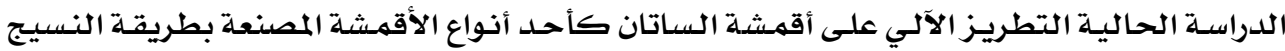

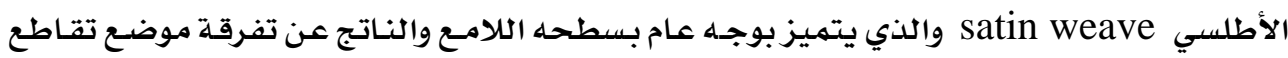

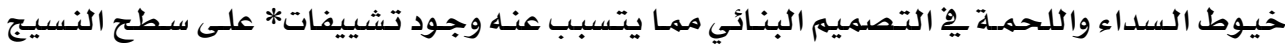

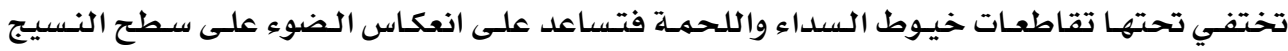

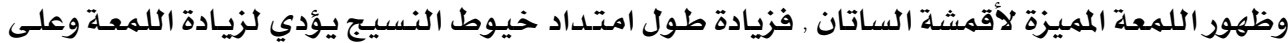

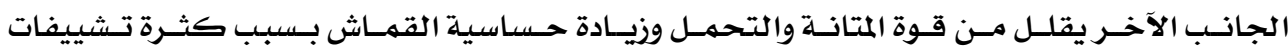

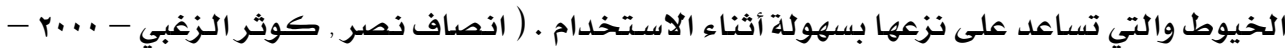

$(r) \Lambda, r \cdot q$

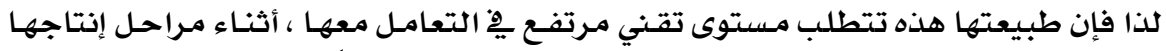

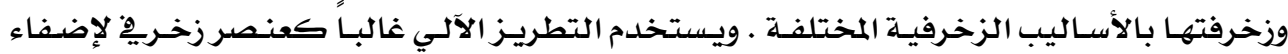

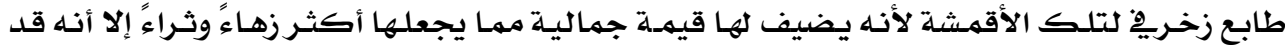

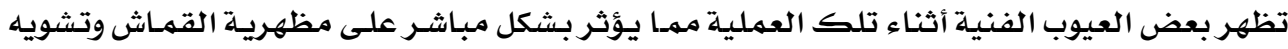

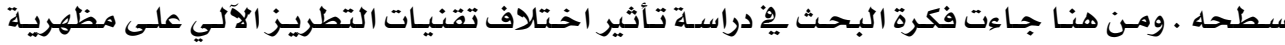




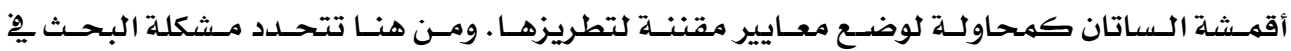
التساؤلات الآتيـة : التهان

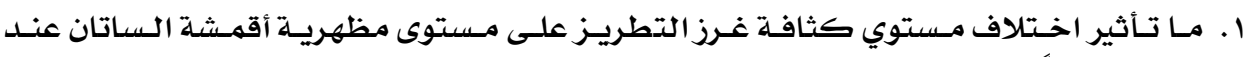

$$
\text { تطريزها آليا ؟ }
$$

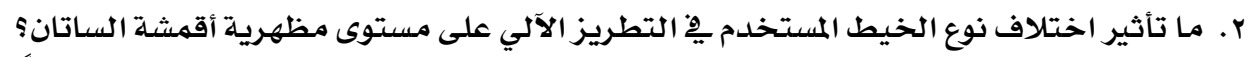

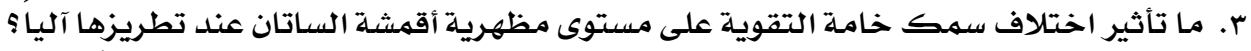

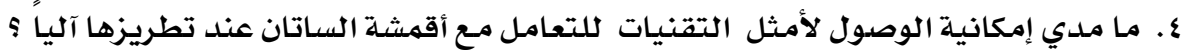

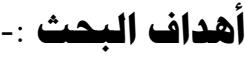

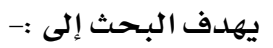

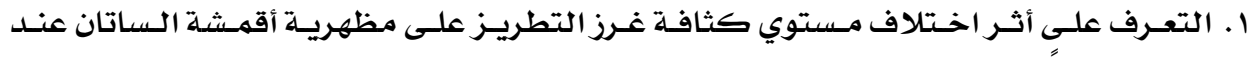

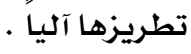

r. التعرف على أثر اختلاف نوع خيط التطريز على مظهرية أقهشة الساتان عند تطريزها آلياً .

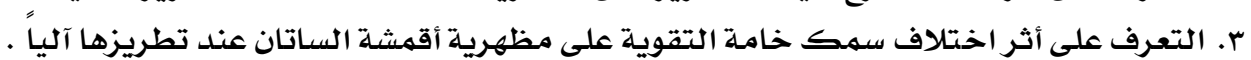

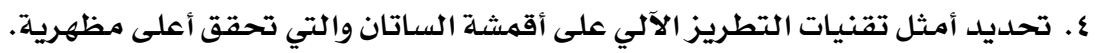

\section{أهميـة البمث : أهمثية}

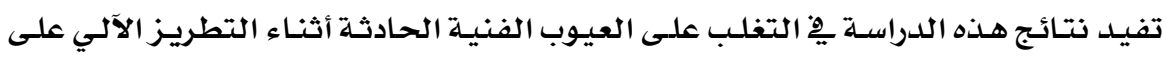
أقمشـة السـاتان وتحديد جوانب ونواحي القصور فيها , والتي قد تنتج عن الاختيـار الخـاطئ (لمستوى

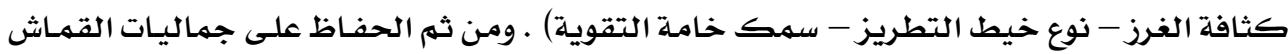
ومظهرية التطريز عليه .

هدود البصث: -

$$
\text { يقتصر هذا البحث على : }
$$

• قماش سـاتان "كريب باك" (وزن خفيف -وزن متوسط ) يصلح لتنفيذ ملابس المساء والسهرة

$$
\text { الحريهي }
$$

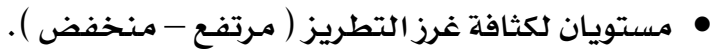

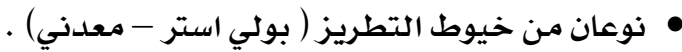

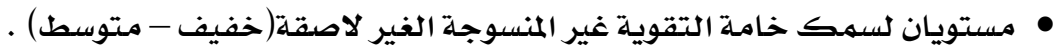

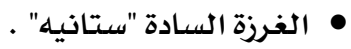

فروض البمث

ا ـ توجد فروق دالة إحصائيا بين متوسطي درجات مظهرية التطريز الآلي لكثافة الغرز (مرتفعة -

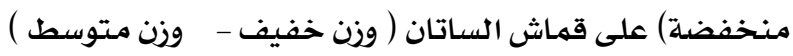




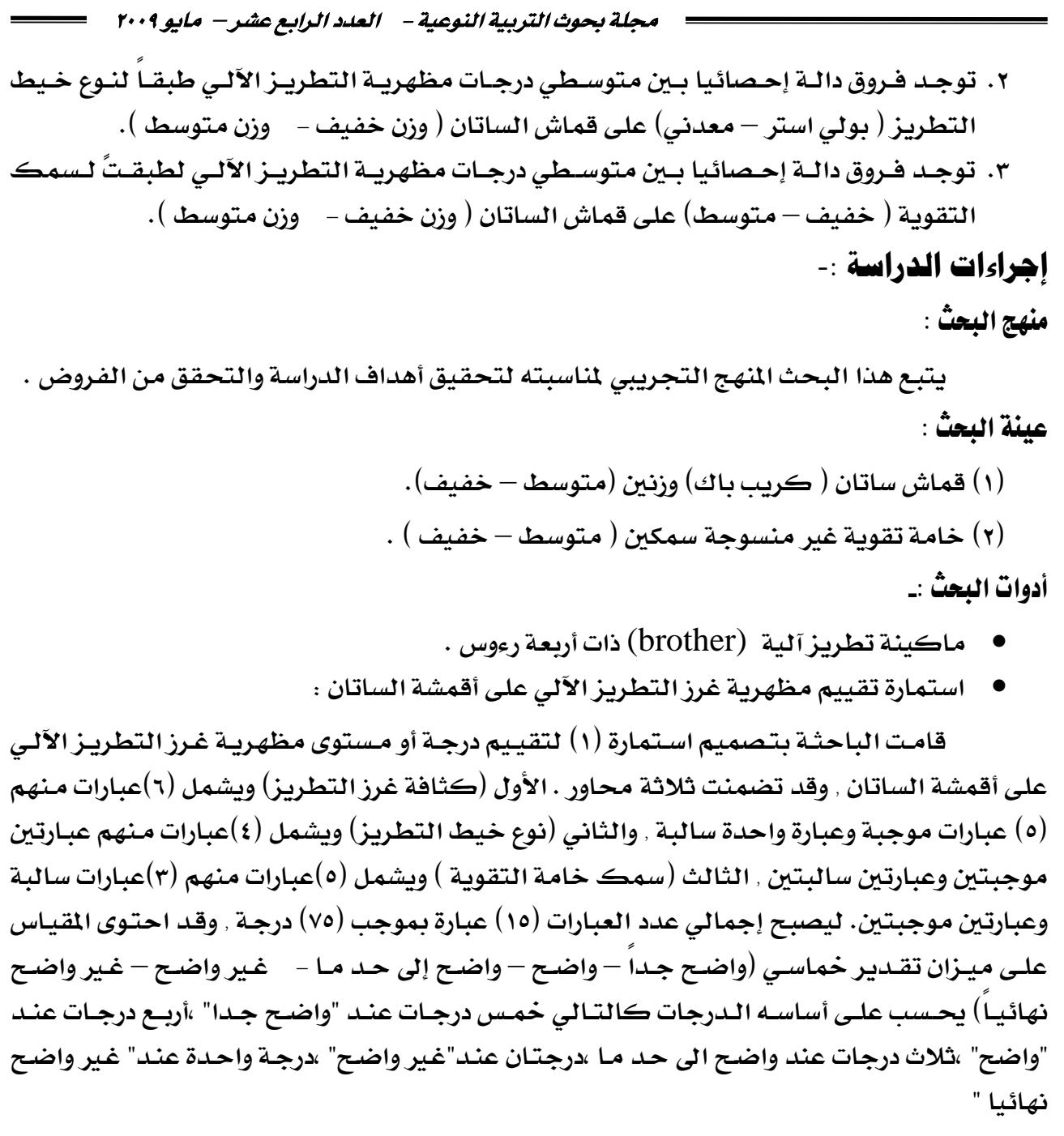

$$
\text { وقد تم التأكد من صدق وثبات الاستمارة كما يلي }
$$

صدق الاستمارة :

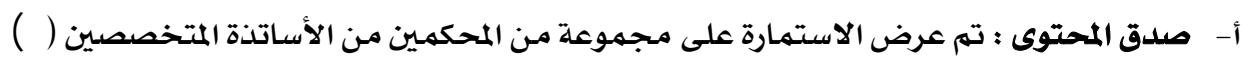

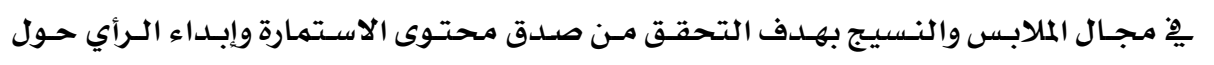

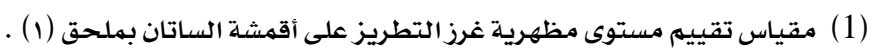

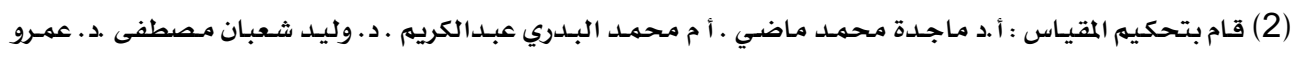

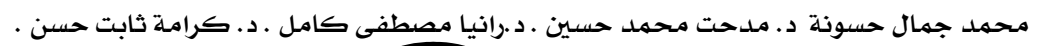


عباراتها ومدى ارتباطها بموضوع البحث, وِِّوضو ضما أسفرت عنه بعض الملاحظات تم التوصل للصورة النهائية للاستمارة . ب- الاتساق الداخلي : تم التحقق من صدق المقياس عن طريق الاتساق الداخلي وذلك بحسـاب

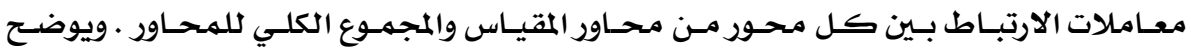

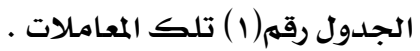

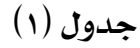

معاملات الارتباط بين كل محور والمجموع الكلي للمحاور

\begin{tabular}{|c|c|}
\hline معامل الارتباط & المحور \\
\hline$\cdot, \mathrm{V} \wedge$ & المحور الأول ( كثافة التطريز) \\
\hline$\cdot 9$. & المحور الثاني ( نوع الخيط ) \\
\hline$\cdot, \wedge \Lambda$ & المحور الثالث(سمك التقويـة ) \\
\hline$\cdot \wedge \mathrm{V}$ & المجموع الكلي للمححاور \\
\hline
\end{tabular}

يتضـح من الجدول السابق أن معامل الارتبـاط ذو دلالـة إحصائية مرتفعـة عند مستوى ا ب,.

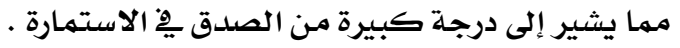
ثبات الاستمارة :

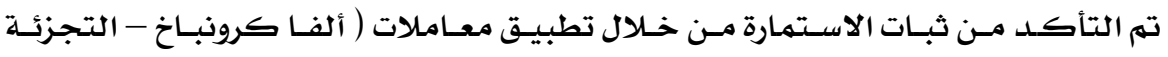
النصفية ) , ويوضـح الجدول رقم (ץ) نتائج الثبات لتطبيق تلك المعاملات :

جدول (r) ( ) ( )

معاملات تحديد ثبات الاستمارة

\begin{tabular}{|c|c|c|}
\hline \multicolumn{2}{|c|}{ معـامـلات الثبـات } & \multirow{2}{*}{ المحاور } \\
\hline التجزئة النصفية & ألفا كرونباخ & \\
\hline$\cdot, \wedge 1$ & •, vo & المحور الأول \\
\hline$\cdot 9 Y$ & $\cdot, \Lambda Y$ & المحور الثاني \\
\hline$\cdot, \wedge 1$ & $\cdot, \mathrm{V} V$ & المحور الثالث \\
\hline
\end{tabular}

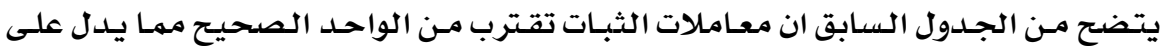
وجود درجـة مـرتفعة من الثبات.

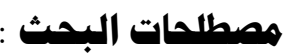

Techniques : تقانات

Technical: تقانة 


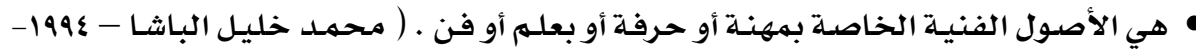

$$
\text { (rNY }
$$

• ويقصد بالتقانة الصفة أو الطريقة التي ينفذ بها ايى عمل وتشمل ترتيب مراحل بناء العمل

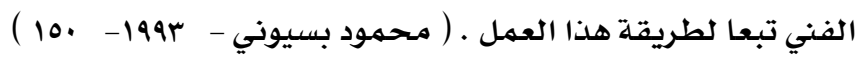

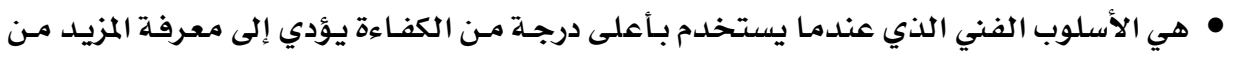

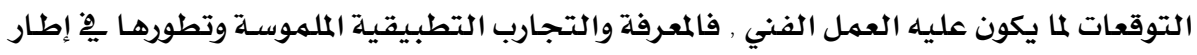

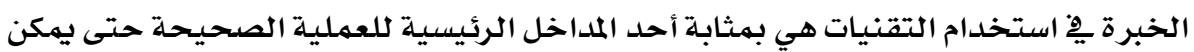

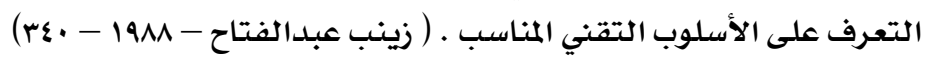

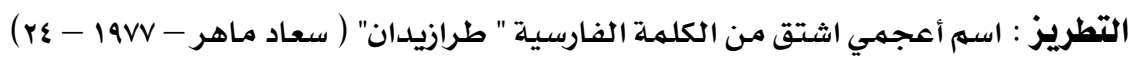

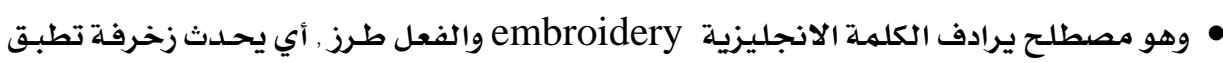

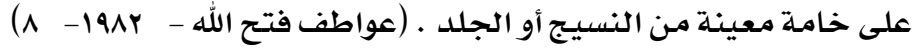

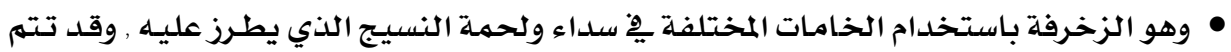

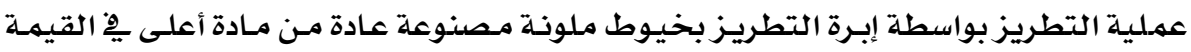

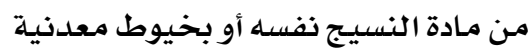

Computerized Embroidery : التطريز الآلى

هـ زخرفـة القمـاش بخيـوط متعـددة الأنواع والألـوان , وبتـأثيرات حديثـة للغـرز باسـتخدام

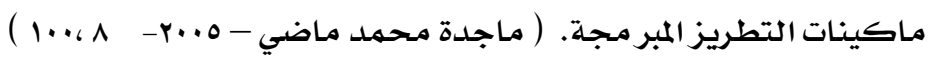

Satin fabrics : أقششة الساتان

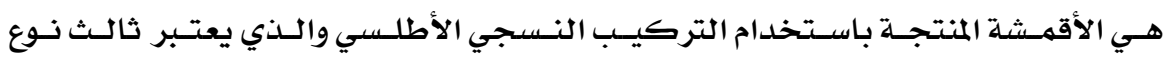

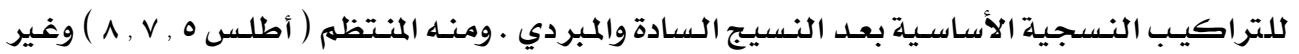

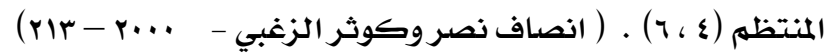

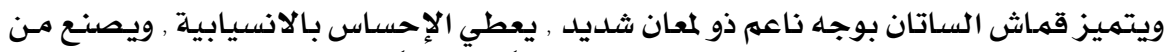

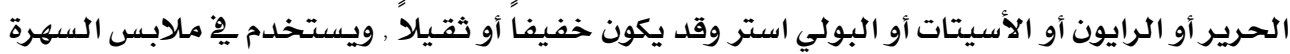

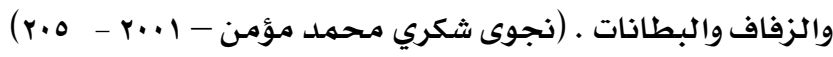

وللساتان أنواع عديدة منها :

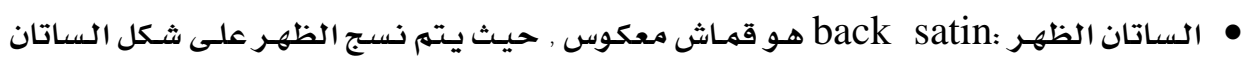

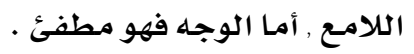

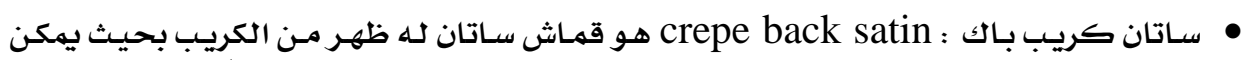

استـخدامه على أي مـن الوجهين , ويتميز بسطح لامـع وظهر مطفي نسبياً , ويتميز بثنايـاه

الناعمة (Shaeffer, s.,\& C. - 1994- 491) 


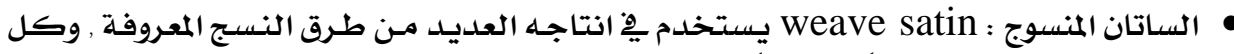

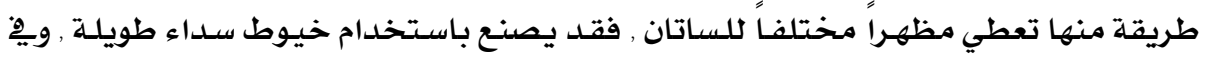

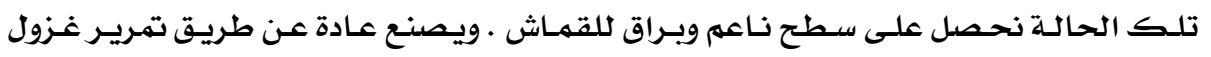

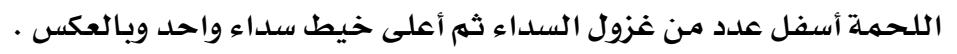

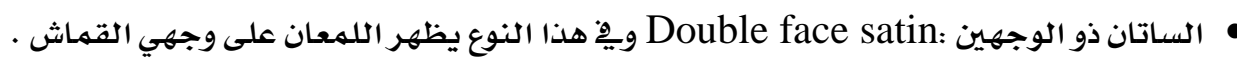

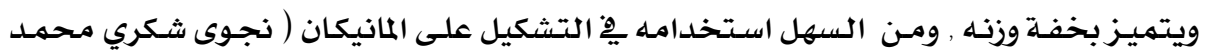

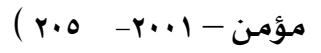

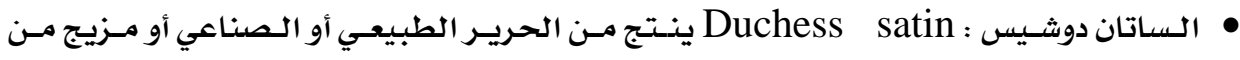

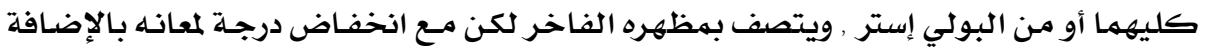

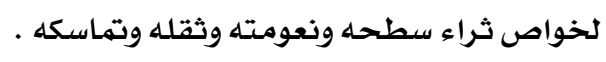

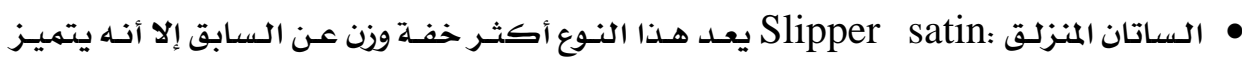

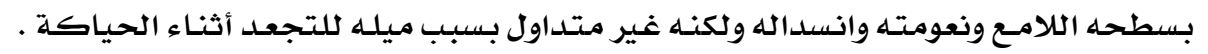

(Silberbery, L., \& Martin, S. - 1992- 36)

خامة التقوية : Supporting Material

هي تلك الخامات التي تستخدم بغرض تدعيم الأقمشة قبل تطريزها إما بشكل مؤقت حتى

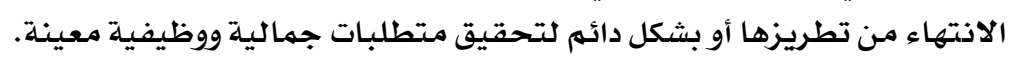

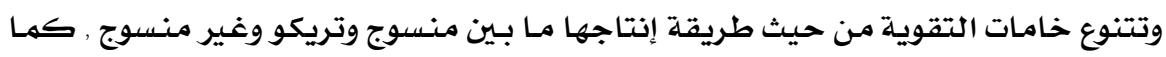

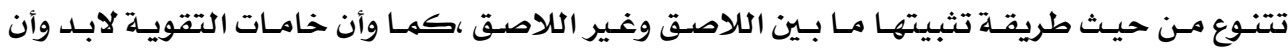

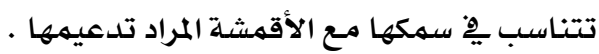

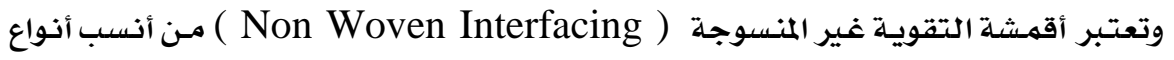

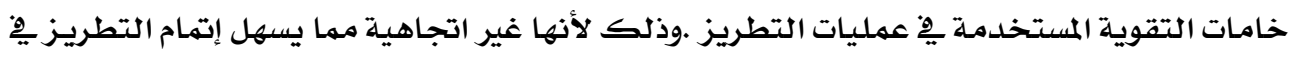

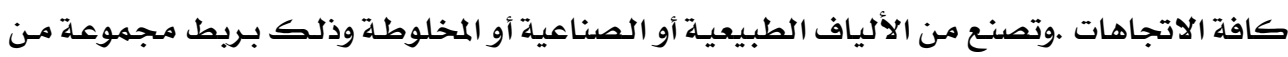

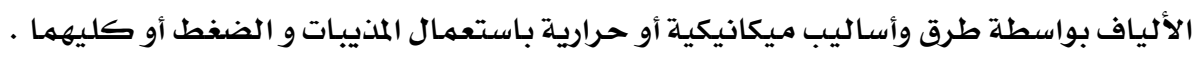

تقسم خامات التقوية غير المنسوجة إلى :

• • خامات التقوية غير الكلاصقة .

• خامات التقوية اللاصقة .

أولاً خامات التقوية غير اللاصقة :

هي خامات تقوية غير اتجاهية تلاءم الأقمشة المتماسكة النسيج كالساتان و التويل ويهكن

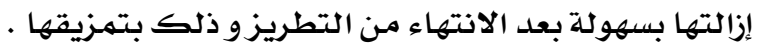




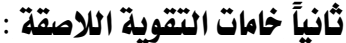

هي خامـات تقوية لها نفس خصائص الخامـات غير اللاصقة وهي تزود بسطح لاصـق عليـه

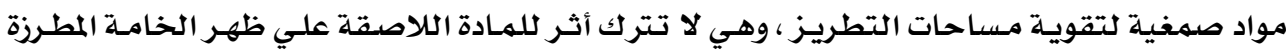

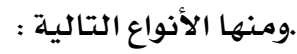

: Tear away 0

يعتبر الحشو اللاصـق القابـل للتمـزق الاختيـار الأكثر شيوعا بـين شـركات التطريز الآلي

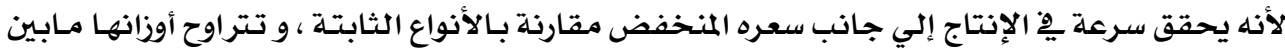

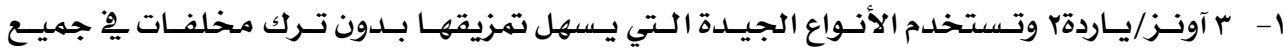

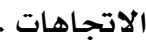

: Cut away الحشو الثابت

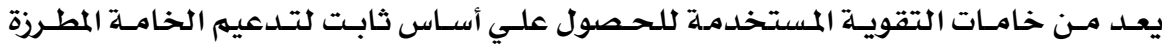

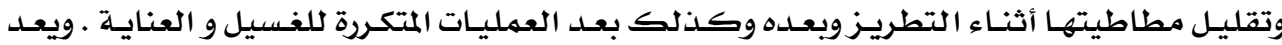
الأكثر مقاومـة للتثقيب بإبرة الماكينة من الحشو القابل للتهزق بالإضافة إلي أنه يعطي ثباتـا عاليا

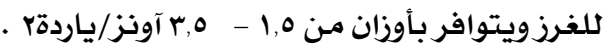

: Water soul able الحشو القابل للدوبان

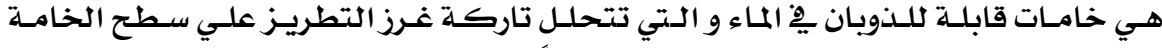

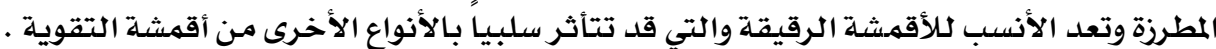

: Poly mesh البولي ميث 0

هي خامـات تعطي درجـة تقويـة عاليـة ، وتنـاسـب أقمشـة التريكو السـادة والبيكيـة والانتر لوك كما أنها تناسب الأقمشة المنسوجلة.

: Weblon 0

وهـي تـشبـه البـولي مـيش إلا أنهـا تـــــع مـن أليـاف النـايلون ، وتنـاسبـ الأقمسشـة الخفيفـة والرقيقة .

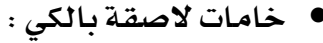

و تلك نوعية من أقمشة التقوية يتهم تثبيتها بالحرارة باستخدام المكواة أو مكابس خاصـة .

(www.fabrics-manufacturers.com/satin-weave.html) 
اـ دراسة (نفيسة عبلالرحمن عفيفي - 1997) عنوانها :

" تأثير أساليب التطريز على النسيج السادة والأطلسي والوبري ـ دراسة مقارنة "

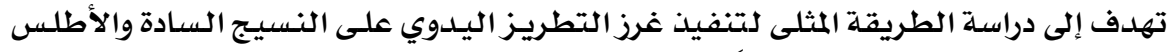

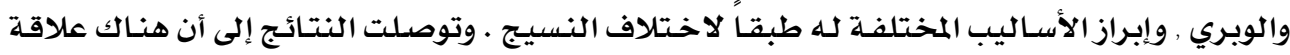

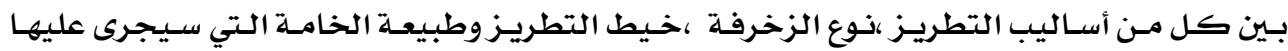

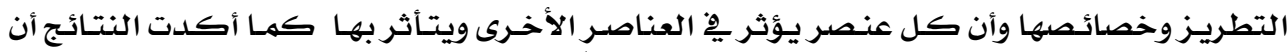

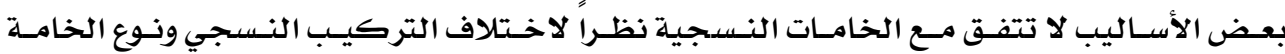

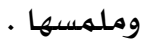

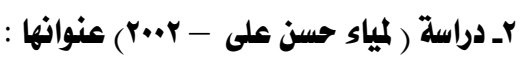

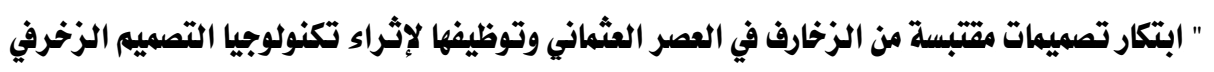

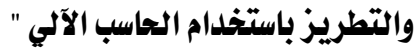

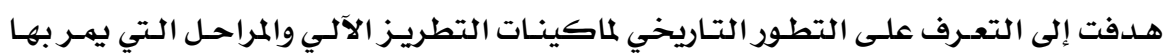

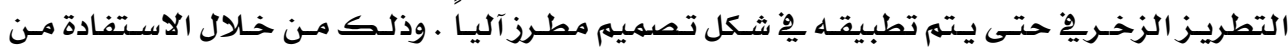

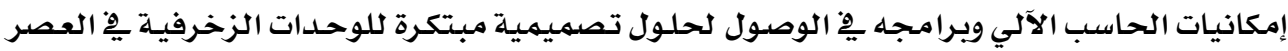

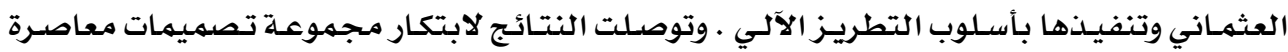

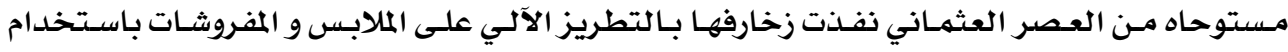

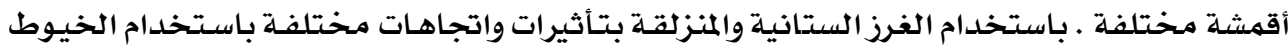
الحريرية.

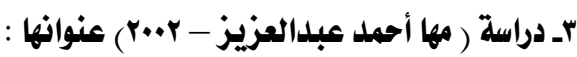
" دراسة مقارية لبعض أساليب التطريز اليدوي والآلي على الأقمشة النسيجية الحديثة والاستفادة منها

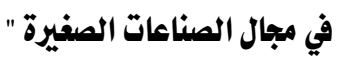

وتهدف إلى وضع معايير مقننة عند اختيار الأسلوب الأمثل للتطريز على الأقمشة النسجية

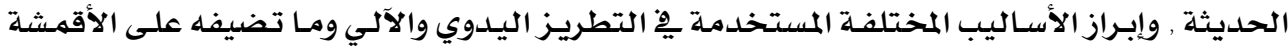

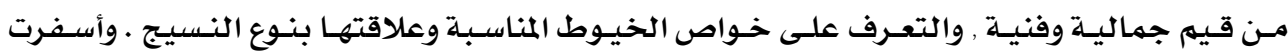

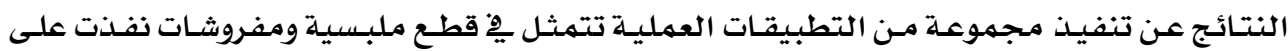

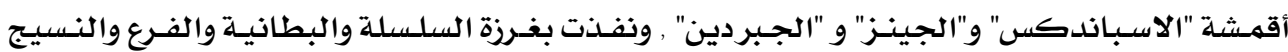

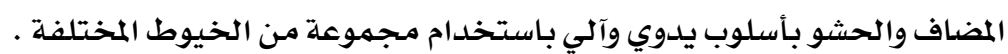


كـ دراسة ( عماد الدين سيل جوهر - ب..ץץ) عنوانها :

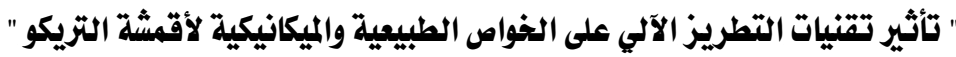

هدفت إلى دراسلة الخواص الطبيعيـة والميكانيكيـة لأقهمشة تريكو اللحمـة للتعـرف على مـدى

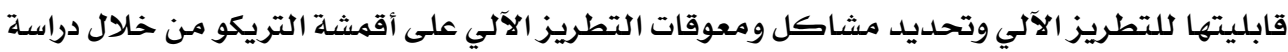
أثر بعض تقنيات التطريز الآلي ( نهـرة الإبرة - نوع غرزة التطريز - كثافة الغـرزة ) ومـن أهـم النتائج الته

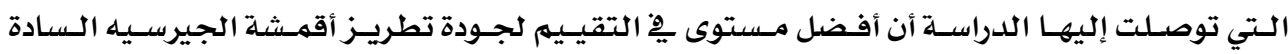

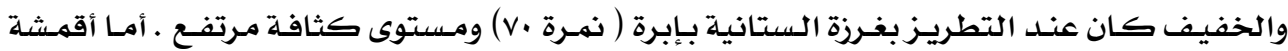

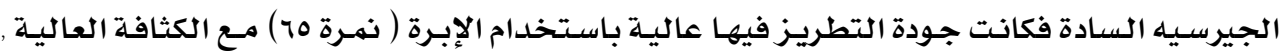

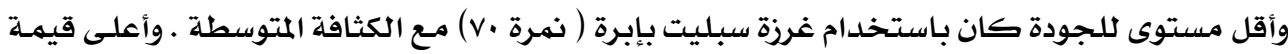

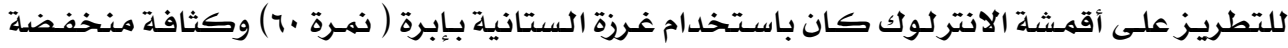

للغرز - للغ

هـ دراسة ( أسماء محمود محمد - - +••r ) عنوانها :

\section{" أسس وتقنيات زخرفة الملابس الجلدية بالتطريز الآلي"}

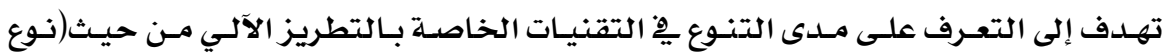

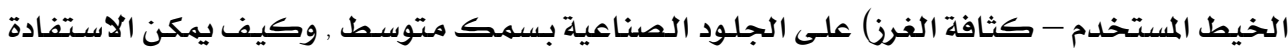

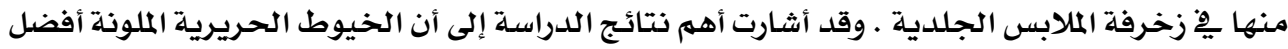

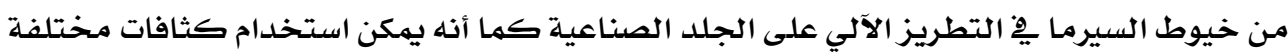

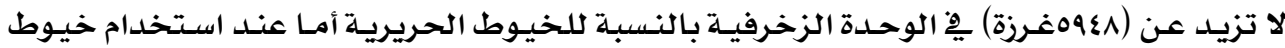

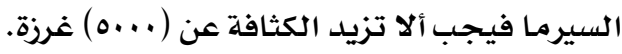

مـن العـرض السـابق للدراسـات يتــح أن معظمهـا تنـاول أسـاليب وتقنيـات التطريـز الآلـي

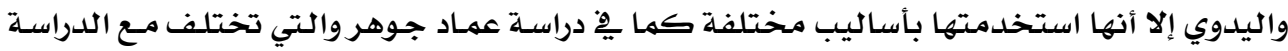

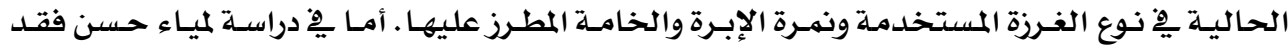

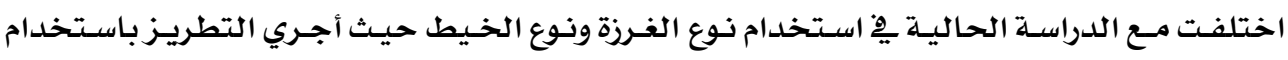

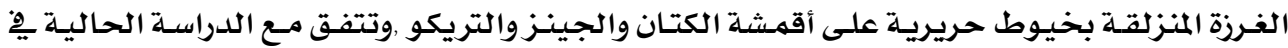

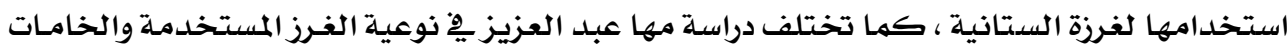

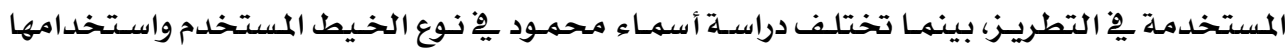

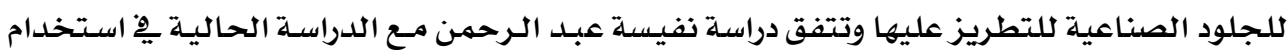

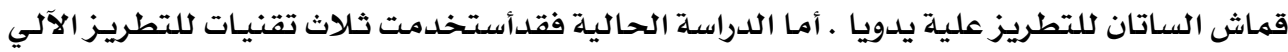
( كثافة غرز التطريز - نوع خيط التطريز - سمك خامسة التقويـة ) للتطريز على أقمشـة السـاتان/ ليكرا (أطلس ه ) كريب باكة (وزن خفيف - وزن متوسط ) ). 
(1) تم تطريزوحدة زخرفيـه مـن الطبيعة ( فراشـة) لتحقق الامتداد يِّ الاتجاهـات المختلفة للتطريز

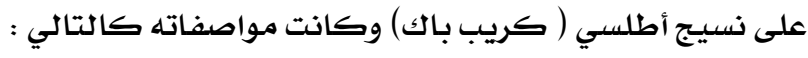

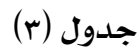

مواصفات قماث الساتان محل الدراسـة

\begin{tabular}{|c|c|c|c|c|}
\hline \multicolumn{2}{|c|}{ سـاتان خفيف } & \multicolumn{2}{|c|}{ سـاتان متوسط } & \multirow{2}{*}{ البيان } \\
\hline مواصفة اللحمات & مواصفة السـداء & مواصفة اللحمـات & مواصفة السداء & \\
\hline 0ـ فتلة/سهم & r افتلة/سه & • ع فتلة/سم & •0 افتلة/سم & عدد الخيوط \\
\hline ا ا دنير & l/V. دنير & l/V. إنير & ا ا دنير & نهـرة الخيط \\
\hline ذيكرا/بولي & بولي استر & ليكرا/بولي & بولي استر & الخـامـة \\
\hline \multicolumn{2}{|c|}{.اجم/קr. } & \multicolumn{2}{|c|}{ عاجم/קr } & الوزن \\
\hline \multicolumn{2}{|c|}{ أطلسيه عدة r } & \multicolumn{2}{|c|}{ أطلسيه عدة r } & التركيب النسج \\
\hline
\end{tabular}

خامة التقوية غير منسوجة وكانت مواصفاتها كالتالي : (r)

جدول (๕)

مواصفات خامسة التقويـة

\begin{tabular}{|c|c|c|}
\hline السمكك & 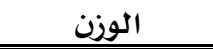 & نوع خـامـة التقويـة \\
\hline$\cdot, r \varepsilon$ & م, Y آونز /ياردةب & متوسط(Tear away) \\
\hline$\cdot, I r$ & 1, آونز /ياردةr & خفيف)(Tear away) \\
\hline
\end{tabular}

\section{نتائج البحث وتفسيرها}

$$
\text { ينص الفرض الأول على أنه }
$$

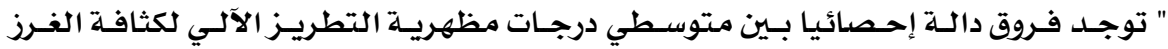

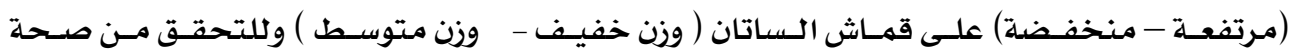

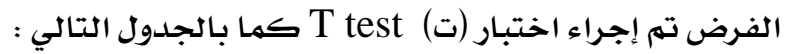


جدول (0)

دلالة الفروق بين مظهرية التطريز الآلي لكثافتي غرز التطريز على قماش الساتان

( وزن خفيف- وزن متوسط )

\begin{tabular}{|c|c|c|c|c|c|c|c|}
\hline مستوي الدلالة & الحرجية & المحسوبة & العينة & الانحراف & الحسابي & كثافة & القماش \\
\hline \multirow{2}{*}{ دال لصنالح كثافة } & \multirow[b]{2}{*}{ Tr } & \multirow{2}{*}{$1,9 \pi$} & \multirow{2}{*}{ rr } & $1, Y 19$ & o,rvo & مرتفعة & \multirow{2}{*}{$\bar{s}$} \\
\hline & & & & $1, \times 90$ & $7,9 \ldots$ & منخفضة & \\
\hline \multirow{2}{*}{ دال الغرز المرتفعة عند كثافة } & \multirow[b]{2}{*}{ זי } & \multirow[b]{2}{*}{$r, \cdot \varepsilon$} & \multirow[b]{2}{*}{ rr } & I, riv & $v, 99$ & مرتفعة & \multirow{2}{*}{ 秀 } \\
\hline & & & & $1,1 \Lambda$. & $v, r \Lambda$ & منخفضة & \\
\hline
\end{tabular}

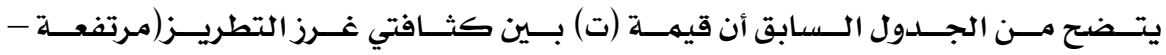

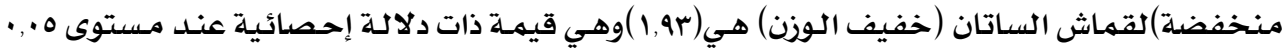

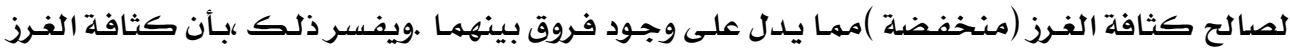

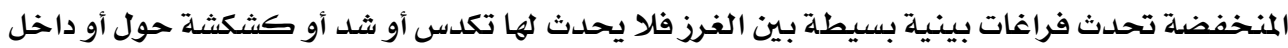

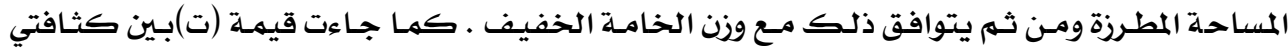

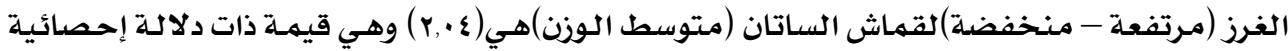

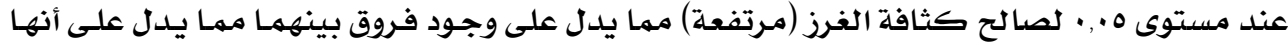

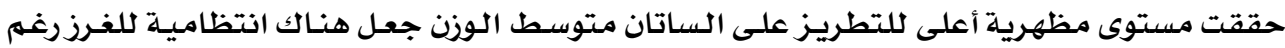

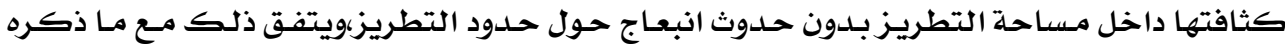

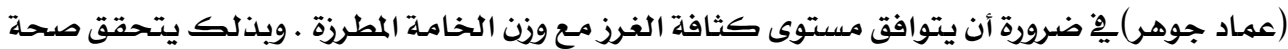

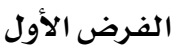

$$
\text { ينص الفرض الثاني على أنه }
$$

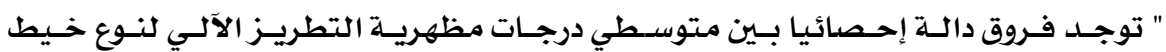

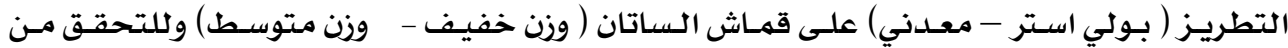

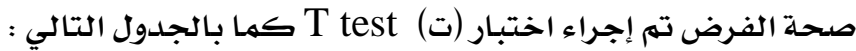


جدول (7) (ج) (9)

دلالة الفروق بين مظهرية التطريز الآلي لنوعي خيط التطريز على قماش الساتان

( وزن خفيف- - وزن متوسط )

\begin{tabular}{|c|c|c|c|c|c|c|c|}
\hline مستوي الدلالة & الحرجية & المحسوبة & العينة & الانحراف & الحسابي & نوع الخيط & القماش \\
\hline \multirow{2}{*}{ 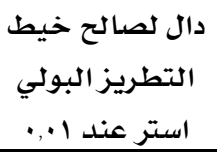 } & \multirow[b]{2}{*}{ Tr } & \multirow[b]{2}{*}{$\vee, \varepsilon \wedge$} & \multirow[b]{2}{*}{ rr } & $\cdot, 109$ & 7,01 & بولي استر & \multirow{2}{*}{$\bar{s}$} \\
\hline & & & & $1, \cdot \cdot$ & $\varepsilon, V V$ & معدني & \\
\hline \multirow{2}{*}{ التطريز البولي خيط } & \multirow[b]{2}{*}{ Tr } & \multirow[b]{2}{*}{ T, Vo } & \multirow[b]{2}{*}{ rr } & $\cdot$, • VaA & $\Lambda, \varepsilon \wedge$ & بولي استر & \multirow{2}{*}{ 票 } \\
\hline & & & & $1, \cdot .4 \mathrm{r}$ & $7,9$. & & \\
\hline
\end{tabular}

يتضح من الجدول السابق أن قيمة (ت) بين نوعي خيط التطريز (البولي استر - المعدني)

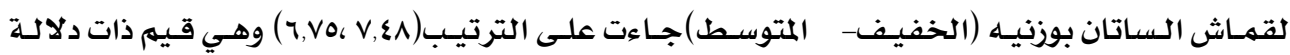

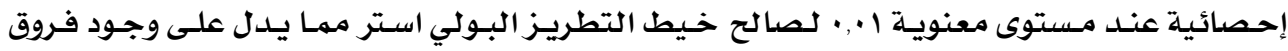

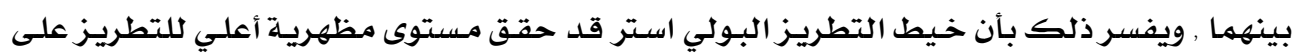

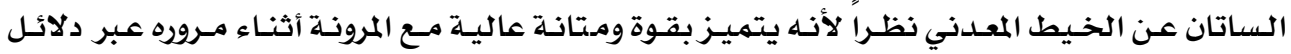

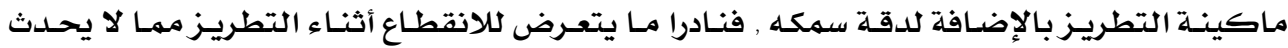
انزلاقا للغرز أو عدم تكونها , وبذلك يتحقة صالافة صحة الفرض الثاني

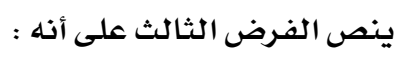

" توجد فروق دالة إحصائيا بين متوسطي درجـات مظهريـة التطريز الآلي لسمك التقويـة

$$
\text { (خفيف - موسط) على قماش الساتان ( وزن خفيف - وزن متوسط دان ). }
$$

جدول (v) دلالة الفروق بين مظهرية التطريز الآلي لنوعي خيط التطريز على قماش الساتان

\begin{tabular}{|c|c|c|c|c|c|c|c|}
\hline مستوي الدلالة & درجات & $\begin{array}{c}\text { المحسوبة } \\
\end{array}$ & حجمه & الانحراف & الحسابي & سمك & وزن القماش \\
\hline دال لصالح سمك & \multirow[b]{2}{*}{ Tr } & \multirow[b]{2}{*}{ r,ror } & \multirow[b]{2}{*}{ rY } & $1,19 \varepsilon$ & 0, rVO & خفيف & \multirow{2}{*}{$\bar{y}$} \\
\hline التقوية المتوسط هـ. & & & & 1,r79 & $7, \cdot$. & متوسط & \\
\hline \multirow{2}{*}{ التقوية المتوسط سمك } & \multirow{2}{*}{ r } & \multirow{2}{*}{$1,7 \cdot V$} & \multirow[b]{2}{*}{ rY } & 1,ro9 & $v, \Sigma \Sigma 4$ & خفيف & \multirow{2}{*}{$\begin{array}{l}\text { 電 } \\
\text { 等 }\end{array}$} \\
\hline & & & & $1, \cdot \varepsilon V$ & 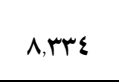 & متوسط & \\
\hline
\end{tabular}

( وزن خفيف- وزن متوسط ) 


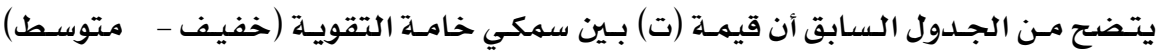

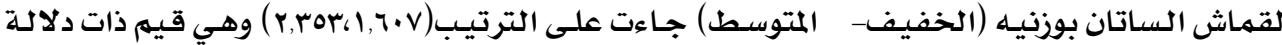

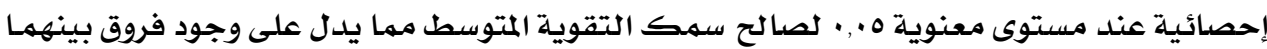

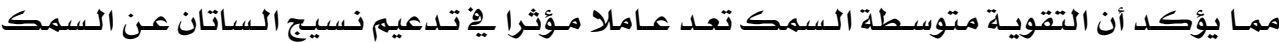

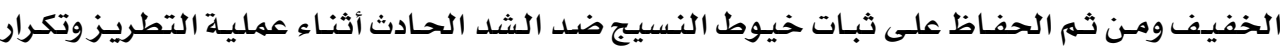

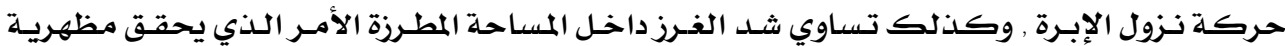
مرتفعة للتطريز وثبات أبعاده .وبذلك يتحقق صحة الفرض الثران الثالث . جدول) (^)

ترتيب عينات البحث طبقا لأفضلية مظهريتها تبعاً لوزن القماش (الخفيف - المتوسط )

\begin{tabular}{|c|c|c|c|}
\hline الترتيب & المئوية & العيــنة & وزنماث \\
\hline 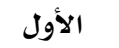 & $\%$. & كثافة منخفضدة - خيط بولي استر - تقوية متوسطة & \multirow{8}{*}{ 京 } \\
\hline 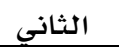 & $\%$ \% & كثافة منخفضة - خيط بولي استر - تقوية خفيفة & \\
\hline 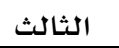 & $\% 70$ & كثافة مرتفعة - خيط بولي استر - تقوية متوسطة & \\
\hline 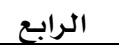 & $\%$. & كثافة مرتفعة - خيط بولي استر - تقويـة خفيفة & \\
\hline الخامس & $\%$ & كثافة منخفضدة - خيط معدني - تقوية متوسطة & \\
\hline السـادس & $\%$. & كثافة مرتفعة - خيط معدني - تقويـة متوسطة & \\
\hline السـابع - ابع & $\%$ ६० & كثافة منخفضدة - خيط معدني - تقوية خفيفة & \\
\hline الثامن & $\%$. & كثافة مرتفعة - خيط معدني - تقوية خفيفة & \\
\hline 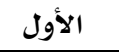 & $\%$. & كثافة مرتفعة - خيط بولي استر - تقوية متوسطة & \multirow{8}{*}{ 哥 } \\
\hline 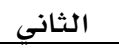 & $\% \wedge \vee$ & كثافة مرتفعة - خيط بولي استر - تقوية خفيفة & \\
\hline 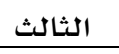 & $\%$ & كثافة منخفضدة - خيط بولي استر - تقويـة متوسطة & \\
\hline 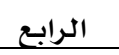 & $\%$. & كثافة منخفضة - خيط بولي استر - تقوية خفيفة & \\
\hline 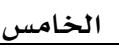 & $\% \vee \varepsilon$ & كثافة مرتفعة - خيط معدني - تقويـة متوسطة & \\
\hline السـادس & $\%$ \% & كثافة منخفضة - خيط معدني - تقوية متوسطة & \\
\hline السـابع & $\%$. & كثافة مرتفعة - خيط معددني - تقوية خفيفة & \\
\hline الثامن & $\%$. & كثافة منخفضة - خيط معدني - تقوية خفيفة & \\
\hline
\end{tabular}

يوضح الجدول السابق ما يلي :

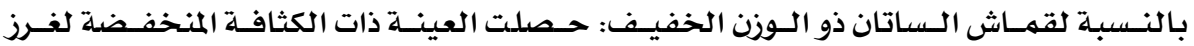

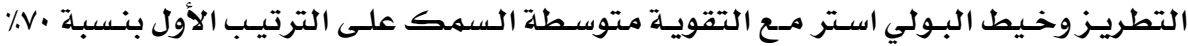

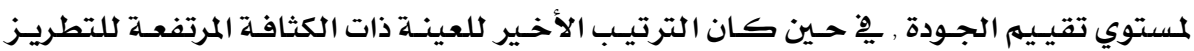

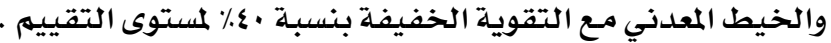




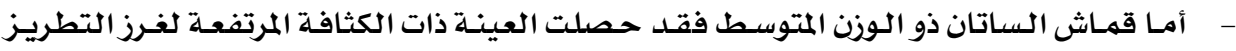

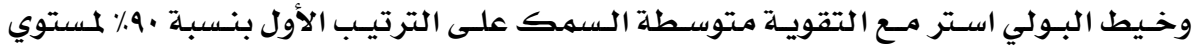

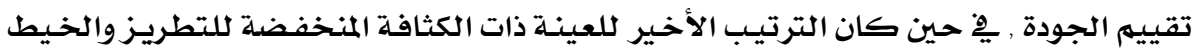

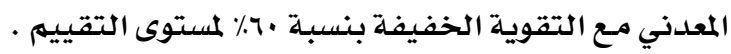

ا- إجراء المزيد من الدراسات التجريبية المماثلة للدراسـة الحالية والعمل على اشتقاق متغيرات

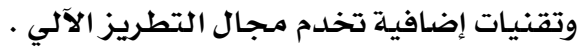

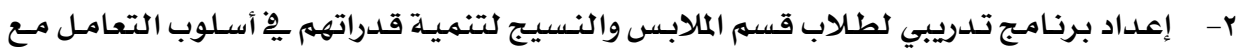

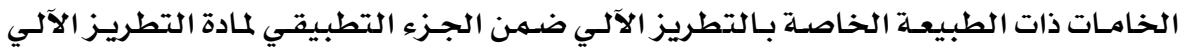

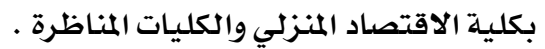

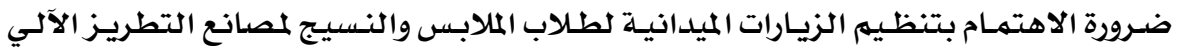

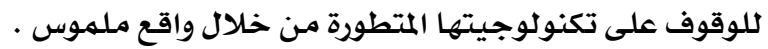

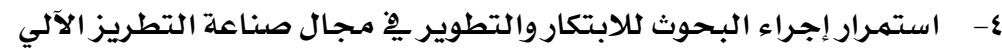

أسماء محمود محمد "أسس وتقنيات زخرفة المالابس الجلدية بـالتطريز الآلي " رسـالة ماجستير -

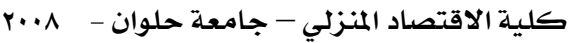

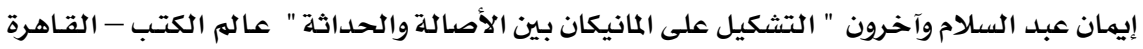
$. r \cdot r-$ أنصاف نصر وكوثر ألزغبي "دراسات ِِّ النسيج "- دار الفكر العربي - القاهرة - .... ب.

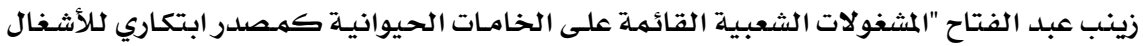
الفنية " رسالة دكتوراه - كلية التربية الفنية - جامعة حلوان - 1911 .

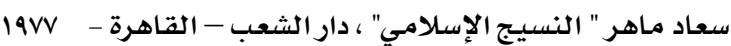

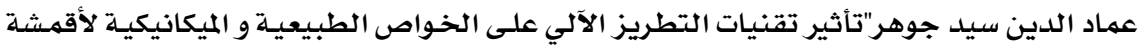

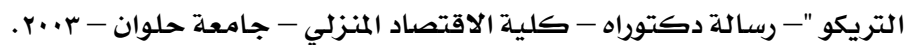

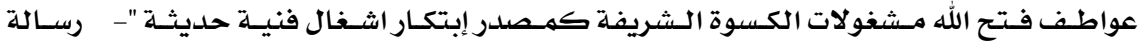

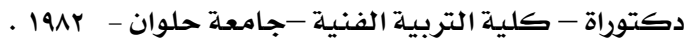

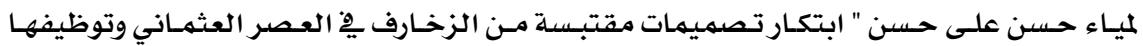
$-\wedge$ لإثراء تكنولوجيا التصميهم ألزخريفِ والتطريز باستخدام الحاسب الآلي" رسـالة دكتوراه - كليـة

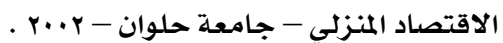
ماجدة محمد ماضي وآخرون الموسوعة يْ فن وصناعة التطريز - دار المصطفى - القاهرة - م..r.

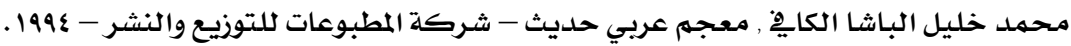




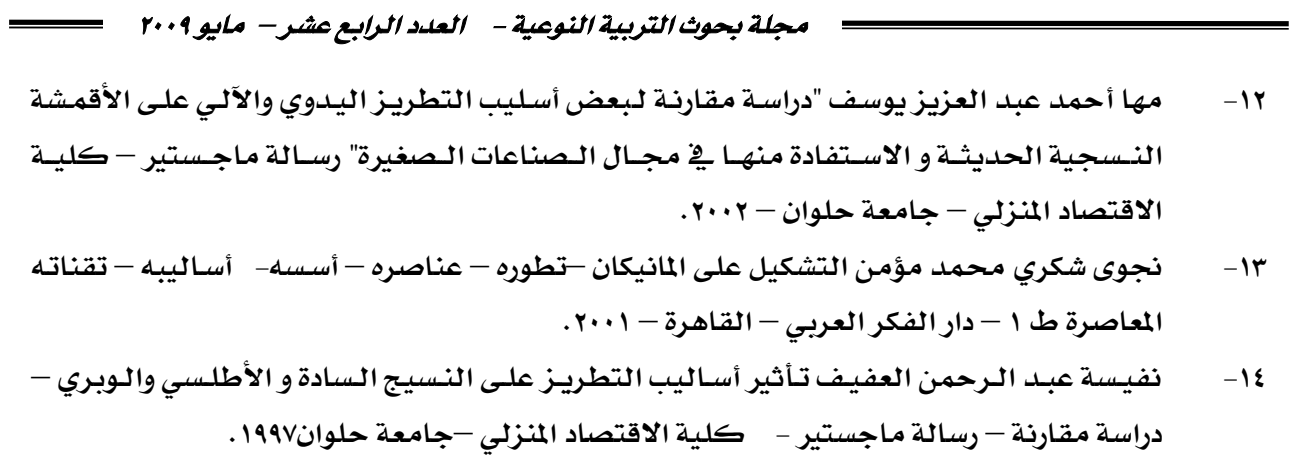

15- Shaeffer, s.,\& C Fabric sewing guide,Chilton book co. Randor, Pennsylvania, U.S.A.,1994

16- Silberbery, L., \& Martin The art of dress modeling, butter Worth Heinemann, Ltd. Linaer house, Jardn hill, Oxford, 1992.

17- http://www.fabrics-manufacturers.com/satin-weave.html

18- http://www.hollingsworth-vose.com /products/industrial/embroidery 
(1)

استمارة تقيييم مظهرية غرز التطريز على أقشة الساتان

\begin{tabular}{|c|c|c|c|c|c|c|}
\hline \multicolumn{5}{|c|}{ مستوى التقييم } & \multirow[b]{2}{*}{ عناصر التقييم } & \multirow[b]{2}{*}{ 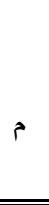 } \\
\hline فهائ & واضير & حاضى حدما & 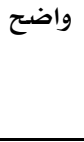 & جداضح & & \\
\hline \multirow{18}{*}{ نهائيا } & & & & & \multicolumn{2}{|c|}{ المحور الأول : كثافة غرز التطريز : } \\
\hline & & & & & مدى انتظام كثافة التطريز داخل المساحة المطرزة . & -1 \\
\hline & & & & & درجة تساوي شد غرز التطريز . & $-r$ \\
\hline & & & & & درجة سمك المساحة المطرزة . & $-r$ \\
\hline & & & & & وجود تجعد أو كشكشة حول حدود المساحة المطرزة & $-\varepsilon$ \\
\hline & & & & & مدى توافق خيط التطريز مـع طبيعة الخامـة المطرزة . & -0 \\
\hline & & & & & المستوى الجمالي للقطعة المنفذة . & -7 \\
\hline & & & & & \multicolumn{2}{|c|}{ المحور الثاني :نوع خيط التطريز : } \\
\hline & & & & & درجة صلابة المساحة المطرزة . & -1 \\
\hline & & & & & مدى توافق نوع الخيط مـع المظهر السطحي للخامة المطرزة & $-r$ \\
\hline & & & & & وجود غرز منزلقة داخل المساحة المطرزة . & $-r$ \\
\hline & & & & & المستوى الجمالي للقطعة المطرزة . & $-\varepsilon$ \\
\hline & & & & & \multicolumn{2}{|c|}{ المحور الثالث : سمك خامة التقوية } \\
\hline & & & & & درجة صلابة المساحة المطرزة . & -1 \\
\hline & & & & & درجة تساوي شد غرز التطريز . & $-r$ \\
\hline & & & & & وجود تجعد أو كشكشة حول حدود المساحة المطرزة & $-r$ \\
\hline & & & & & وجود غرز منزلقة داخل المساحسة المطرزة . & $-\varepsilon$ \\
\hline & & & & & المستوى الجمالي للقطعة المطرزة . & -0 \\
\hline
\end{tabular}

